\title{
AKTIVITAS ANTIMALARIA SENYAWA FLAVANON TERISOPRENILASI DARI KULIT BATANG Erythrina fusca $\mathrm{L}$.
}

\author{
Novi Fatmawati, Novi Anggreini, Ratih Dewi Saputri, Tjitjik Srie Tjahjandarie, Mulyadi Tanjung* \\ Natural Products Chemistry Research Group, Organic Chemistry Division, \\ Department of Chemistry, Faculty of Science and Technology, Universitas Airlangga, Surabaya 60115, Indonesia \\ *Corresponding Author : mulyadi-t@fst.unair.ac.id
}

Submit : 11 Januari 2018 Accepted : 20 April 2018

\begin{abstract}
Two isoprenylated flavanones namely as lonchocarpol A (1) dan lupinifolin (2) were isolated from the stem bark of Erythrina fusca L. Their structures were determined based on spectroscopic data such as UV, IR, MS and NMR. Compounds 1-2 were evaluated for their antimalarial against Plasmodium falciparum strain 3D7 showing their $\mathrm{IC}_{50}$ were 1.18 and $0.8 \mu \mathrm{g} / \mathrm{ml}$, respectively and very high activity.
\end{abstract}

Keywords : Erythrina fusca L., lonchocarpol A, lupinifolin, antimalarial

\section{PENDAHULUAN}

Malaria merupakan salah satu penyakit tropis yang menyebabkan kematian terutama anak-anak. Penyakit ini disebabkan oleh gigitan nyamuk yang mengandung parasit Plasmodium antara lain Plasmodium falciparum. Erythrina fusca L. yang dikenal dengan nama dadap cangkring. Tumbuhan ini dimanfaatkan oleh masyarakat sebagai obat demam, sakit gigi, batuk, melancarkan haid, dan sebagai obat malaria [1]. Pemanfaatan tumbuhan ini dalam pengobatan tradisional tentunya berhubungan dengan senyawa aktif yang terdapat dalam tumbuhan $E$. fusca $\mathrm{L}$.

Flavonoid merupakan senyawa fenolik utama yang ditemukan pada genus Erythrina [2]. Ciri khas senyawa flavonoid pada genus Erythrina mempunyai substituen isoprenil $\left(\mathrm{C}_{5}\right)$ dan geranil $\left(\mathrm{C}_{10}\right)$ yang terikat pada inti aromatik flavonoid. Senyawa flavonoid Erythrina terdiri dari golongan pterokarpan, flavonoid, neoflavonoid dan isoflavonoid. Senyawa flavonoid Erythrina. memperlihatkan aktivitas biologis yang menarik antara lain sebagai antimalaria dan antikanker [3-5].

Penelitian ini bertujuan untuk mengisolasi dan mengidentifikasi senyawa flavanon terisoprenilasi dari kulit batang Erythrina fusca L. Pada kesempatan kali ini akan dilaporkan tentang isolasi dua senyawa flavanon terisoprenilasi, yakni lonkokarpol A (1) dan lupinifolin (2) dari kulit batang E. fusca L. Selain itu juga akan dilaporkan aktivitas antimalaria kedua senyawa flavanon terisoprenilasi terhadap Plasmodium falciparum starin 3D7 yang sensitif terhadap klorokuin.

\section{METODE PENELITIAN \\ Prosedur umum \\ Spektrum UV ditetapkan dengan spektrofotometer UV-Vis Shimadzu 1800.} Spektrum IR ditentukan dengan spektrofotometer IR Perkin Elmer. Spektrum massa ditentukan dengan spektrometer HR-ESI-MS merck Waters LCT XE ESI. Spektrum NMR ditentukan dengan spektrometer NMR JEOL ECA 400 yang beroperasi pada $400 \mathrm{MHz}\left({ }^{1} \mathrm{H}-\mathrm{NMR}\right)$ dan 100 $\mathrm{MHz}\left({ }^{13} \mathrm{C}-\mathrm{NMR}\right)$. Kromatografi kolom gravitasi menggunakan silika gel 60 (Merck), kromatografi radial menggunakan silika gel 60 $\mathrm{PF}_{254}$ (Merck) dan kromatografi lapis tipis (KLT) menggunakan plat KLT silika gel $60 \mathrm{GF}_{254} 0.25$ $\mathrm{mm}$ (Merck).

\section{Sampel penelitian}

Sampel penelitian yang digunakan dalam penelitian berupa kulit batang dari tumbuhan $E$. fusca L. yang diperoleh dan diidentifikasi di Kebun Raya LIPI Purwodadi, Jawa Timur.

\section{Ekstraksi dan isolasi flavonoid terisoprenilasi}

Ekstraksi kulit batang E. fusca L. sebanyak 2,5 $\mathrm{kg}$ menggunakan metanol pada suhu kamar sebanyak dua kali selama 24 jam. Ekstrak metanol yang diperoleh dipekatkan dengan alat penguap bertekanan rendah sehingga diperoleh ekstrak kental metanol berwarna coklat $(250 \mathrm{~g})$. Ekstrak metanol selanjutnya dipartisi 
dengan $n$-heksana menghasilkan ekstrak $n$ heksana dan ekstrak metanol. Ekstrak metanol selanjutnya ditambahkan asam sulfat 5\% pH 3-4 kemudian dipartisi dengan etil asetat menghasilkan ekstrak etil asetat dan fasa asam. Ekstraksi ini bertujuan untuk memisahkan senyawa flavonoid dan alkaloid [6,7]. Pemisahan ekstrak etil asetat $(21 \mathrm{~g})$ dengan kolom vakum cair menggunakan campuran eluen $n$-heksana:etil asetat $(9: 1,8: 2$, dan 1:1) menghasilkan empat fraksi utama A-D. Berdasarkan analisis KLT,<smiles>CC(C)=CCc1c(O)c([I+]C=C(C)C)c(O)c2c1O[C@H](c1ccc(O)cc1)CC2=O</smiles>

fraksi B memperlihatkan pendaran warna ungu dengan lampu UV. Pemisahan fraksi D dengan kromatografi kolom gravitasi dengan eluen $n$ heksana:etilasetat (9:1 sampai 7:3) menghasilkan tiga subfraksi $B_{1}-B_{3}$. Pemurnian subfraksi $B_{2}$ dilakukan dengan kromatografi radial dengan menggunakan eluen $n$-heksana:aseton (9:1 sampai 4:1) menghasilkan senyawa lonkokarpol (1) sebanyak $15 \mathrm{mg}$ dan lupinifolin (2) sebanyak $9 \mathrm{mg}$.

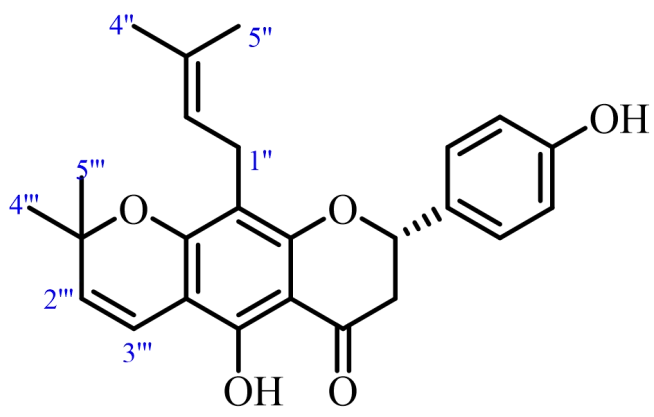

(2)

Gambar 1. Struktur lonkokarpol A (1) dan lupinifolin (2)

\section{Uji aktivitas antimalaria}

Penentuan uji aktivitas antimalaria senyawa 1-2 terhadap Plasmodium falciparum strain 3D7 yang sensitif terhadap klorokuin menggunakan modifikasi Trager dan Jensen dalam medium RPMI 1640 dan $5 \%$ serum darah $\mathrm{O}[8,9]$. Penentuan aktivitas antimalaria masingmasing senyawa dilarutkan dalam DMSO dan dibuat variasi konsentrasi uji sebanyak triplo $(100 ; 50 ; 10 ; 5 ; 50$ dan $1 ; 0,5$ dan $0,1 \mu \mathrm{g} / \mathrm{ml})$. Klorokuin diphosfat digunakan sebagai kontrol positif dan kontrol negatif menggunakan sel darah merah.

Bahan uji dilarutkan dalam DMSO dalam berbagai konsentrasi sebanyak $20 \mu \mathrm{L}$ larutan dan

\begin{abstract}
diencerkan dengan $180 \mu \mathrm{L}$ medium lengkap (medium RPMI 1640 yang ditambahkan 5\% serum darah O) hingga diperoleh berbagai macam kadar. Bahan uji diinkubasi selama 48 jam, dibuat hapusan darah tipis dan diwarnai dengan pewarna Giemsa. Hapusan darah diamati menggunakan mikroskop dengan perbesaran 5000 kali untuk menghitung jumlah eritrosit yang terinfeksi. Analisis data nilai $\mathrm{IC}_{50}$ ditentukan berdasarkan persentase daya hambat parasetamia menggunakan aplikasi program SPSS. Persentase daya hambat parasitemia ditentukan menurut persamaan:
\end{abstract}

$$
\% \text { Hambatan }=100 \%-\left(\frac{\text { Rerata } \% \text { penghambatan parasitemia perlakuan }}{\text { Rerata } \% \text { penghambatan parasitemia } \text { kontrol }} \times 100 \%\right)
$$

\section{HASIL DAN PEMBAHASAN}

Dua senyawa flavanon terisoprenilasi, yakni lonkokarpol A (1) dan lupinifolin (2) telah berhasil diisolasi dari ekstrak etil asetat kulit batang E. fusca L. Struktur kedua senyawa ditetapkan berdasarkan spekroskopi UV, IR, MS, 1D dan 2D NMR.

Lonkokarpol A (1) berwujud padatan kuning memperlihatkan ion kuasimolekul positif $[\mathrm{M}+\mathrm{H}]^{+}$pada $m / z \quad 409,2015$ yang sesuai dengan rumus molekul $\mathrm{C}_{25} \mathrm{H}_{28} \mathrm{O}_{5}$ berdasarkan analisis spektrum HRESIMS. Spektrum UV senyawa 1 dalam metanol memberikan serapan maksimum pada $\lambda_{\text {maks }}(\log \varepsilon): 208(4,75), 257(4,81), 306 s h$ $(4,80)$ yang merupakan ciri khas senyawa flavanon [10]. Spektrum IR senyawa 1 dalam $\mathrm{KBr}$ memperlihatkan pita serapan pada $v_{\text {maks: }}$ : $3425(\mathrm{OH}), 1726(\mathrm{C}=\mathrm{O}$ lakton terkonyugasi $)$, 1546-1448 $(\mathrm{C}=\mathrm{C}$ aromatik) dan 1124 (eter). Spektrum ${ }^{1} \mathrm{H}-\mathrm{NMR}$ (400 MHz, Tabel-1) senyawa 
1 dalam $\mathrm{CDCl}_{3}$ memperlihatkan tiga buah sinyal proton doublet doublet pada $\delta_{\mathrm{H}} 5,30(1 \mathrm{H}, d d, J=$ $13,0 ; 3,0 \mathrm{~Hz} ; \mathrm{H}-2), \delta_{\mathrm{H}} 3,03(1 \mathrm{H}, d d, J=17,0$; $13,0 \mathrm{~Hz} ; \mathrm{H}-3 \mathrm{ax})$, dan $\delta_{\mathrm{H}} 2,79(1 \mathrm{H}, d d, J=17,0$; $3,0 \mathrm{~Hz}, \mathrm{H}-3_{\mathrm{eq}}$ ) yang merupakan ciri khas struktur flavanon [2]. Spektrum ${ }^{1}$ H-NMR senyawa 1 memperlihatkan sinyal proton aromatik yakni sepasang sinyal doublet $(J=8,4 \mathrm{~Hz})$ pada $\delta_{\mathrm{H}}$ $7,30\left(\mathrm{H}-2^{\prime} / 6\right.$ ') dan $\delta_{\mathrm{H}} 6,85\left(\mathrm{H}-3^{\prime} / 5^{\prime}\right)$ yang khas untuk aromatik monosubstitusi di cincin B [2]. Dengan tidak adanya sinyal proton aromatik pada cincin A menunjukkan adanya substituen di C-6 dan C-8. Sinyal singlet pada $\delta_{\mathrm{H}} 12,30$ merupakan ciri proton hidroksi (C-5) yang membentuk chelat dengan karbonil di C-4. Sinyal proton kedua gugus isoprenil yang terikat di C-6 dan C-8 ditandai adanya dua sinyal triplet dari proton vinilik $(J=7,0 \mathrm{~Hz})$ pada $\delta_{\mathrm{H}} 5,22\left(\mathrm{H}-2\right.$ ' '), $\delta_{\mathrm{H}} 5,20$ (H-2','), dua sinyal doublet metilen $(J=7,2 \mathrm{~Hz})$ pada $\delta_{\mathrm{H}} 3,33\left(\mathrm{H}-1\right.$ "'), $\delta_{\mathrm{H}} 3,28(\mathrm{H}-1$ ',') serta empat sinyal singlet metil pada $\delta_{\mathrm{H}} 1,80\left(\mathrm{H}-4\right.$ ' '), $\delta_{\mathrm{H}} 1,73$ (H-4"'), $\delta_{\mathrm{H}} 1,70\left(\mathrm{H}-5\right.$ "'), dan $\delta_{\mathrm{H}} 1,68$ (H-5"'). Spektrum ${ }^{13} \mathrm{C}$ NMR (percobaan APT, $100 \mathrm{MHz}$ ) senyawa 1 memperlihatkan 23 sinyal atom karbon yang mewakili 25 sinyal karbon. Sinyal karbon pada $\delta_{\mathrm{C}} 78,6, \delta_{\mathrm{C}} 43,3$ dan $\delta_{\mathrm{C}} 196,8$ merupakan ciri khas untuk kerangka senyawa flavanon. Tiga sinyal karbon oksiaril pada $\delta_{\mathrm{C}}$ $162,5, \delta_{\mathrm{C}} 159,4$ dan $\delta_{\mathrm{C}} 156,2$ menunjukkan senyawa flavanon merupakan turunan naringenin (5,7,4'-trihidroksi flavanon). Berdasarkan analisis spektrum ${ }^{1} \mathrm{H}$ dan ${ }^{13} \mathrm{C}$ NMR maka senyawa 1 adalah 6,8-diisoprenil-5,7,4'trihidroksi flavanon atau dikenal sebagai lonkokarpol A [11]. Penempatan sinyal proton dan sinyal karbon senyawa 1 didukung oleh spektrum HMQC dan HMBC seperti terlihat pada Gambar 2.

Tabel 1. Data spektrum NMR senyawa lonkokarpol A (1) dalam $\mathrm{CDCl}_{3}$.

\begin{tabular}{|c|c|c|c|}
\hline No. $\mathrm{C}$ & $\delta_{\mathrm{H}}(\mathrm{mult}, J \mathrm{~Hz})$ & $\boldsymbol{\delta}_{\mathrm{C}}$ & HMBC \\
\hline 2 & $5,30(d d, 13,0,3,0)$ & 78,6 & C-1', C-2'/6', C-4 \\
\hline 3 & $\begin{array}{l}3,03(d d, 13,0,17,0)_{\mathrm{ax}} \\
2,79(d d, 17,0,3,0)_{\mathrm{ea}}\end{array}$ & 43,3 & $\begin{array}{l}\text { C- } 2, \text { C-1', C- } 4, \\
\text { C- } 4,\end{array}$ \\
\hline 4 & - & 196,8 & - \\
\hline $4 \mathrm{a}$ & - & 102,9 & - \\
\hline 5 & - & 159,4 & - \\
\hline 6 & - & 107,4 & - \\
\hline 7 & - & 162,5 & - \\
\hline 8 & - & 106,6 & - \\
\hline $8 \mathrm{a}$ & - & 157,9 & - \\
\hline 1 ' & - & 130,9 & - \\
\hline $2^{\prime} / 6^{\prime}$ & $7,30(d, 8,4)$ & 127,3 & $\mathrm{C}-2, \mathrm{C}-2^{\prime} / 6^{\prime}, \mathrm{C}-3^{\prime} / 5^{\prime}, \mathrm{C}-4^{\prime}$ \\
\hline $3^{\prime} / 5$ ' & $6,85(d, 8,4)$ & 115,6 & $\mathrm{C}-1^{\prime}, \mathrm{C}-3^{\prime} / 5^{\prime}, \mathrm{C}-4^{\prime}$ \\
\hline 4' & - & 156,2 & 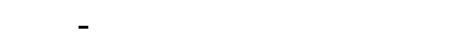 \\
\hline $1 "$ & $3,33(d, 7,2)$ & 22,0 & C-5; C-6, C-7; C-2", C-3" \\
\hline $2 "$ & $5,22(t, 7,2)$ & 122,0 & C-1", C-4", C-5" \\
\hline $3 "$ & - & 134,8 & \\
\hline $4 "$ & $1,80(s)$ & 17,9 & C-2", C-3", C-5" \\
\hline $5 "$ & $1,70(s)$ & 25,9 & C-2", C-3", C-4" \\
\hline $1 "$, & $3,28(d, 7,2)$ & 21,3 & C-7; C-8, C-8a; C-2"', C-3"' \\
\hline $2 " ’$ & $5,20(t, 7,2)$ & 121,8 & C-1"', C-4"', C-5"” \\
\hline $3 " '$ & - & 134,0 & - \\
\hline 4"'” & $1,73(s)$ & 17,8 & C-2"', C-3"', C-5"” \\
\hline $5^{\prime \prime}$ & $1,68(s)$ & 25,9 & C-2"', C-3"', C-4"” \\
\hline $5-\mathrm{OH}$ & $12,30(s)$ & - & C-4a, C-5, C-6 \\
\hline
\end{tabular}

Lupinifolin (2) berwujud padatan kuning dan memperlihatkan ion kuasimolekul positif $[\mathrm{M}+\mathrm{H}]^{+}$pada $m / z 407,1863$ yang sesuai dengan rumus molekul $\mathrm{C}_{25} \mathrm{H}_{26} \mathrm{O}_{5}$ berdasarkan analisis spektrum HRESIMS. Spektrum UV dan IR senyawa 2 dalam metanol memberikan serapan maksimum pada $\lambda_{\text {maks }}(\log \varepsilon): 210(4,80), 276$
$(4,85), 302$ sh $(4,86) \mathrm{nm}$ dan spektrum IR memperlihatkan pita serapan pada $v_{\text {maks: }} 3417$ $(\mathrm{OH}), 1715(\mathrm{C}=\mathrm{O}$ lakton terkonyugasi $), 1535$ $1450(\mathrm{C}=\mathrm{C}$ aromatik) dan 1126 (eter) yang mirip dengan senyawa 1 [10]. Spektrum ${ }^{1} \mathrm{H}-\mathrm{NMR}$ (400 $\mathrm{MHz}$, Tabel-2) senyawa 2 dalam $\mathrm{CDCl}_{3}$ memperlihatkan tiga buah sinyal proton doublet 
doublet pada $\delta_{\mathrm{H}} 5,35(1 \mathrm{H}, d d, J=12,9 ; 3,1 \mathrm{~Hz}$; $\mathrm{H}-2), \delta_{\mathrm{H}} 3,05\left(1 \mathrm{H}, d d, J=17,1 ; 12,9 \mathrm{~Hz} ; \mathrm{H}-3_{\mathrm{ax}}\right)$, dan $\delta_{\mathrm{H}} 2,81\left(1 \mathrm{H}, d d, J=17,1 ; 2,9 \mathrm{~Hz}, \mathrm{H}-3_{\text {eq }}\right)$ serta sepasang sinyal aromatik monosubstitusi $(J$ $=8,6 \mathrm{~Hz})$ pada $\delta_{\mathrm{H}} 7,34$ dan 6,88 yang mirip dengan senyawa 1. . Spektrum ${ }^{1} \mathrm{H}-\mathrm{NMR}$ senyawa 2 memperlihatkan adanya sinyal proton hidroksi, isoprenil dan pirano. Sinyal singlet pada $\delta_{\mathrm{H}} 12,26$ merupakan ciri khas dari proton hidroksi $(5-\mathrm{OH})$ yang membentuk chelat dengan karbonil di C-4. Sinyal proton isoprenil terdiri dari satu sinyal proton vinilik pada $5,16(t, J=7,4 \mathrm{~Hz}, \mathrm{H}-2$ '' $)$, satu sinyal doublet metilen pada $\delta_{\mathrm{H}} 3,21(d, 7,4$ $\mathrm{Hz} ; \mathrm{H}-1$ "') serta dua sinyal singlet metil pada $\delta_{\mathrm{H}}$ $1,80\left(\mathrm{H}-4\right.$ '') dan $\delta_{\mathrm{H}} 1,68(\mathrm{H}-5$ ''). Sinyal proton pirano terdiri dari sepasang sinyal proton cis vinilik $(J=10,0 \mathrm{~Hz})$ pada $\delta_{\mathrm{H}} 6,65(\mathrm{H}-3$ ',') dan $\delta_{\mathrm{H}} 5,51$ (H-2,') serta dua sinyal singlet metil pada $\delta_{\mathrm{H}} 1,46$ (H-4"') dan $\delta_{\mathrm{H}} 1,45$ (H-5"'). Spektrum ${ }^{13} \mathrm{C}$ NMR senyawa 2 memperlihatkan
23 sinyal atom karbon yang mewakili 25 sinyal karbon. Penempatan gugus isoprenil dan pirano ditetapkan berdasarkan analisis spektrum HMQC dan HMBC. Sinyal proton pada $\delta_{\mathrm{H}} 12,26(5-\mathrm{OH})$ memperlihatkan korelasi dengan satu sinyal karbon oksiaril pada $\delta_{\mathrm{C}} 156,6(5-\mathrm{OH})$ dan dua sinyal karbon kuarterner pada $\delta_{\mathrm{C}} 102,7$ (C-4a) dan $\delta_{\mathrm{C}} 102,8(\mathrm{C}-6)$. Sinyal proton cis vinilik dari pirano pada $\delta_{\mathrm{H}} 5,51(\mathrm{H}-2$ "') berkorelasi dengan dua sinyal karbon kuarterner pada $\delta_{\mathrm{C}} 78,1$ (C-1"') dan $\delta_{\mathrm{C}} 102,8$ (C-6). Hasil ni menunjukkan gugus pirano terhubungkan di C-6 dan C-7 sekaligus menempatkan gugus isoprenil terikat di C-8. Berdasarkan analisis spektrum NMR maka senyawa 2 dikenal dengan nama lupinifolin [4]. Korelasi antara sinyal proton dengan sinyal karbon dalam dua atau tiga ikatan pada spektrum HMBC yang utama untuk mendukung struktur senyawa aurapten hasil isolasi dapat dilihat pada Tabel-2 dan Gambar 2.

Tabel 2. Data spektrum NMR senyawa lupinifolin (2) dalam $\mathrm{CDCl}_{3}$.

\begin{tabular}{|c|c|c|c|}
\hline No. C & $\delta_{\mathrm{H}}(\mathrm{mult}, J \mathrm{~Hz})$ & $\delta_{\mathrm{C}}$ & HMBC \\
\hline 2 & $5,35(d d, 12,9 ; 3,1)$ & 78,5 & $\mathrm{C}-1^{\prime}, \mathrm{C}-2^{\prime} / 6^{\prime}$ \\
\hline \multirow[t]{2}{*}{3} & $3,05(d d, 17,1 ; 12,9)$ & 43,3 & C-2. C-4 \\
\hline & $2,81(d d, 17,1 ; 3,1)$ & & \\
\hline 4 & - & 196,4 & - \\
\hline $4 \mathrm{a}$ & - & 102,7 & - \\
\hline 5 & - & 156,6 & - \\
\hline 6 & - & 102,8 & - \\
\hline 7 & - & 159,8 & - \\
\hline 8 & - & 108,6 & - \\
\hline $8 \mathrm{a}$ & - & 159,3 & - \\
\hline 1 ' & - & 131,1 & - \\
\hline $2 ' / 6 ’$ & $7,34(d, 8,6)$ & 127,7 & $\mathrm{C}-2, \mathrm{C}-3{ }^{\prime} / 5^{\prime}, \mathrm{C}-4^{\prime}$ \\
\hline $3 ' / 5$ & $6,88(d, 8,6)$ & 115,5 & C-1', C-2'/6', C-4' \\
\hline 4' & - & 155,8 & - \\
\hline $1 "$ & $3,21(d, 7,4)$ & 21,5 & C-5, C-6, C-7, C-2', C-3' \\
\hline $2 "$ & $5,16(t, 7,4)$ & 122,5 & C-4', C-5', \\
\hline $3 "$ & - & 131,0 & - \\
\hline 4" & $1,80(s)$ & 25,8 & $\mathrm{C}-2{ }^{\prime \prime}, \mathrm{C}-3{ }^{\prime \prime}, \mathrm{C}-5{ }^{\prime}$ \\
\hline $5 "$ & $1,68(s)$ & 17,8 & C-2'', C-3', C-4'” \\
\hline 1 '” & - & 78,1 & - \\
\hline 2 '” & $5,51(d, 10,0)$ & 126,0 & $\mathrm{C}-6, \mathrm{C}-2{ }^{\prime}$, \\
\hline 3 '” & $6,65(d, 10,0)$ & 115,7 & C-5, C-7, C-2', \\
\hline 4 "” & $1,46(s)$ & 28,4 & $\mathrm{C}-1$ '”, C-2'”, C-5'” \\
\hline 5 '” & $1,45(s)$ & 28,3 & C-1"', C-2"', C-4", \\
\hline $5-\mathrm{OH}$ & $12,26(s)$ & 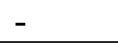 & $C-4 a, C-5, C-6$ \\
\hline
\end{tabular}



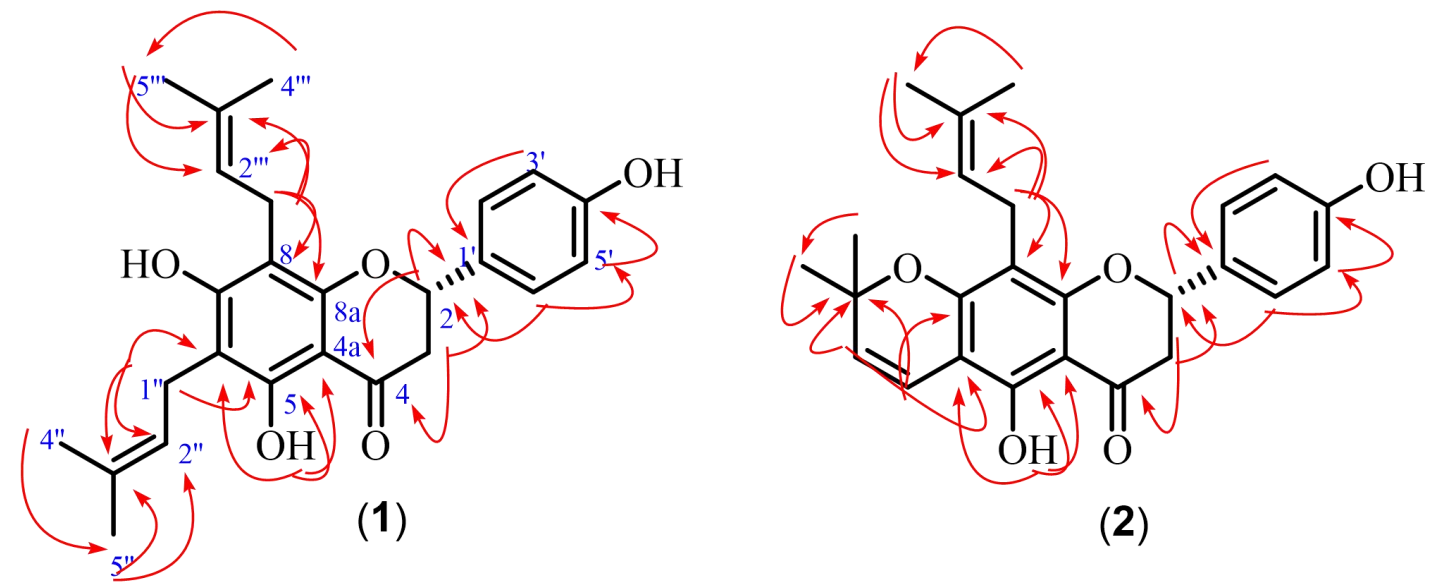

(2)

Gambar 2. Korelasi HMBC yang utama pada senyawa 1-2

Uji aktivitas antimalaria senyawa lonkokarpol A (1) dan lupinifolin (2) hasil isolasi terhadap Plasmodium falciparum strain 3D7 menunjukkan nilai daya hambat konsentrasi $\mathrm{IC}_{50}$ masing-masing senyawa sebesar 1,18 dan 0,82 $\mu \mathrm{g} / \mathrm{ml}$. Hasil aktivitas ini menunjukkan kedua senyawa flavanon terisoprenilasi mempunyai aktivitas antimalaria yang sangat poten. Keaktifan senyawa lupinifolin mempunyai keaktifan yang lebih tinggi dibandingkan klorokuin diphosfat $\left(\mathrm{IC}_{50}=1,03 \mu \mathrm{g} / \mathrm{ml}\right)$. Siklisasi antara gugus hidroksi di C-7 dengan gugus isoprenil di C-6 membentuk cincin piran meningkatkan aktivitas antimalaria dibandingkan senyawa lonkokarpol A.

\section{KESIMPULAN}

Dua senyawa flavanon terisoprenilasi yakni lonkokarpol A (1) dan lupinifolin (2) telah berhasil diisolasi dari kulit batang E. fusca L.. Aktivitas antimalaria senyawa lonkokarpol A (1) dan lupinifolin (2) terhadap Plasmodium falciparum menunjukkan aktivitas yang sangat poten.

\section{UCAPAN TERIMAKASIH}

Ucapan terimakasih disampaikan kepada Prof. Dr. Yana M. Syah yang telah membantu dalam pengukuran spektrum NMR dan HRESIMS.

\section{DAFTAR PUSTAKA}

[1] Herlina, T., Supratman, U., Soedjanaatmadja, U.M.S., Subarnas, A., Sutardjo, S., Abdullah, N.R., Hayashi, H., (2010). Anti-malarial compound from the stem bark of Erythrina variegata, Indonesian J. Chem, 9 (2), 308-311.
[2] Tjahjandarie, T.S., Pudjiastuti, P., Saputri, R.D., Tanjung, M., (2014). Antimalaria and antioxidant activity of phenolic compounds isolated from Erythrina crystagalli L. J. Chem. Pharm. Res. 6, 786-790.

[3] Innok, P., Rukachaisirikul, T., Suksamrarn, A., (2009), Flavanoids and pterocarpans from the bark of Erythrina fusca, Chem. Pharm. Bull, 57(9), 993-996.

[4] Khaomek, P., Ichino, C., Ishiyama, A., Sekiguchi, H., Namatame, M., Ruangrungsi, N., Saifah, E., Kiyohara, H., Otoguro, K., Omura, S., Yamada, H., (2008), In vitro antimalarial activity of prenylated flavonoids from Erythrina fusca, J. Nat Med, 62, 217-220.

[5] Tjahjandarie, T.S., Tanjung, M., (2015). Phenolic compounds from the stem bark of Erythrina orientalis and their cytotoxic and antioxidant activities. Der Pharma Chem, 7(1), 206-211.

[6] Tanjung, M., Saputri, R.D., Tjahjandarie, T.S., (2017). 4-Methoxy-3-(3-methylbut-2en-1-yl)-7-((3-methylbut-2-en-1-yl)oxy) quinolin-2 $(1 \mathrm{H})$-one from Melicope moluccana T.G. Hartley. Molbank. M939. $2,1-5$.

[7] Tjahjandarie, T.S., Tanjung, M., (2015). Lead compound antimalaria dan antioksidan senyawa alkaloid, flavonoid, dan kumarin dari Limonia accidisima L.. Laporan Akhir Penelitian Unggulan Perguruan Tinggi, Universitas Airlangga. $1-45$.

[8] Tanjung, M., Saputri, R.D., Tjahjandarie, T.S., (2016). Antimalarial and antioxidant of isoprenylated coumarins from the stem bark of Mesua borneensis L.. J Biol Active Prod from Nature. 6, 95-100. 
[9] Marliana, E., Tjahjandarie, T.S., Tanjung, M., (2015). Isoprenylated flavanone derivatives from Macaranga hosei King ex Hook F. Der Pharmacia Lettre. 7(3), 153156.

[10] Tanjung M, Mujahidin D, Hakim EH, Darmawan A, Syah Y.M. (2010). Geranylated flavonols from Macaranga rhizinoides. Nat Prod Commun. 5,12091211.

[11] Marliana, E., Tjahjandarie, T.S., Tanjung, M., (2016). Aktivitas antioksidan senyawa flavonoid dari Macaranga pearsonii Merr. J. Kimia Mulawarman. 13(2), 97-100. 